\title{
Placa bloqueada e uso de antimicrobiano local no tratamento de fratura mandibular exposta em equino
}

\author{
[Locking compression plate and use of local antimicrobial in the treatment \\ of exposed mandibular fracture in an equine]
}

\section{"Relato de Caso/Case Report"}

\author{
Armando de Mattos Carvalho ${ }^{1 *}$, William Barella da Rocha ${ }^{2}$, Jéssica Pamela Velasco dos Santos ${ }^{2}$, \\ Hugo Shisei Toma ${ }^{3}$, Marcelo Diniz dos Santos ${ }^{2}$, Kelly Cristiane Ito Yamauchi ${ }^{2}$
}

\author{
${ }^{1}$ Departamento de Clínica e Cirurgia Veterinárias, Escola de Veterinária, Universidade Federal de Minas Gerais, Belo \\ Horizonte-MG, Brasil. \\ ${ }^{2}$ Universidade de Cuiabá (UNIC), Cuiabá-MT, Brasil. \\ ${ }^{3}$ Faculdade de Medicina Veterinária, Universidade Federal de Lavras, Lavras-MG, Brasil. \\ *Autor para correspondência/Corresponding author: E-mail: armandodvm@gmail.com
}

\section{Resumo}

A mandíbula é o osso da cabeça mais comumente fraturado nos equinos, sendo normalmente relacionada ao histórico de trauma. O objetivo deste relato é descrever um caso de fratura exposta de mandíbula em um equino com exsudação serossanguinolenta advinda de fístula localizada na região ventral do ramo horizontal da mandíbula esquerda. $O$ diagnóstico foi realizado com base no histórico, sinais clínicos e avaliação radiográfica. Foi realizada osteossíntese com duas placas bloqueadas, ventral e lateral à mandíbula esquerda, associadas a antibioticoterapia de liberação lenta por meio de implante de cimento ósseo embebido em gentamicina para a estabilização do foco da fratura e controle da infecção no local respectivamente. Após quatro meses do procedimento cirúrgico foi observada consolidação da fratura óssea, sendo realizada a remoção das placas e do cimento ósseo implantados. O paciente recebeu alta médica com completo retorno de suas atividades e sem recidiva do processo infeccioso local.

Palavras-chave: osteossíntese; cimento ósseo; esponja de colágeno; implante de antibióticos.

\begin{abstract}
The mandible is the most commonly fractured head bone in horses and is usually related to the history of trauma. The purpose of this report is to describe an exposed mandible fracture case in one horse with serosanguinous exudate from a fistula located in the ventral region of the horizontal branch of the left mandible. The diagnosis was made based on history, clinical signs and radiographic evaluation. Osteosynthesis was performed with two locked compression plates, associated with slow-release antibiotic therapy through gentamicin-embedded bone cement implantation for stabilization of the fracture and infection control. Four months after the surgical procedure, bone fracture consolidation was observed, and the implanted plates and cement were removed. The patient was discharged with complete return to his activities and without recurrence of the local infectious process.
\end{abstract}

Keywords: osteosynthesis; bone cement; collagen sponge; antibiotic implant.

\section{Introdução}

Fraturas decorrentes de traumas na região da cabeça são comuns na espécie equina, sendo a mandíbula o osso mais acometido, este tipo de lesão resulta na interferência direta na alimentação do animal, inibindo a adequada apreensão dos alimentos (Alves et al., 2008; Nóbrega et al., 2013).
A correção cirúrgica é indicada em caso de instabilidade, deslocamento ou fraturas bilaterais, má oclusão ou impossibilidade de ingestão de alimentos. As principais técnicas de osteossíntese indicadas para mandíbula são: cerclagem, cerclagem associada à resina acrílica, utilização 
oral de barra em forma de U fixa com braçadeira, pino intramedular, fixadores externos e fixação interna utilizando placa e parafuso (Auer, 1999; Auer, 2012).

Há descrição de casos clínicos da fratura mandibular utilizando cerclagem (Freitas et al., 2010), cerclagem associada à resina acrílica (Valadão et al., 1994; Alves et al., 2008), placa de compressão dinâmica (Nóbrega et al., 2013), e placa bloqueada (Kuemmerle et al., 2009). As placas bloqueadas representam uma tecnologia de ponta e são a escolha preferida para o reparo de fraturas craniomaxilofaciais (Auer, 2012), promove melhor estabilização do foco de fratura, sendo apropriada sua utilização em casos de fraturas instáveis localizadas no diastema e no ramo horizontal caudal e ramo vertical da mandíbula (Kuemmerle et al., 2009).

Algumas complicações são frequentemente encontradas no tratamento das fraturas mandibulares em equinos, sendo comum a infecção associada à utilização de implantes. $\mathrm{O}$ tratamento das infecções em cirurgias ortopédicas torna-se um desafio para o médico veterinário, devido à formação de compartimento restrito na cavidade medular com baixo número de células fagocitárias, e à baixa vascularização no local da fratura, que dificulta a penetração de antimicrobianos sistêmicos em concentrações adequadas no local (Kuemmerle et al., 2009; Hayes et al., 2013).

Outro aspecto a ser considerado é a deposição de proteínas que irão formar filme de matriz extracelular (MEC) após a aplicação do implante, servindo como uma plataforma para a adesão de células hospedeiras e colonização de fibroblastos. No entanto, bactérias também têm a capacidade de interagir com a MEC formada sobre o implante, secretar camada de polímeros extracelulares e sintetizar o biofilme, estrutura que possibilita sua proteção contra fagocitose e antimicrobianos (Hayes et al., 2013; Grassi et al., 2017).

A utilização de antimicrobiano dose dependente, como os aminoglicosídeos, associado ao implante possibilita altas concentrações do fármaco ampliando sua penetração no biofilme e tecido necrosado, e eleva a eficácia profilática ou terapêutica do processo infeccioso. Os principais exemplos de aplicação de implantes com antimicrobianos em cirurgias ortopédicas veterinárias são cimento ósseo impregnado com antibiótico e esponja de colágeno impregnada com gentamicina (Hayes et al., 2013).
O objetivo deste artigo é relatar caso de fratura exposta da mandíbula em equino submetido à osteossíntese utilizando placa bloqueada associada à esponja de colágeno e cimento ósseo impregnado com gentamicina.

\section{Descrição do caso}

Foi atendido, no Hospital Veterinário (HV) da Universidade de Cuiabá (UNIC), um equino macho castrado, sem raça definida, com quatro anos de idade e histórico de trauma da face há 20 dias. O proprietário relatou o corte e sangramento na região da mandíbula imediatamente após o trauma da cabeça numa ripa de madeira, e que após o incidente o mesmo passou a apresentar dificuldade na ingestão de alimentos. O animal foi medicado na propriedade com anti-inflamatório sistêmico (Flunixin Meglumine), durante três dias seguidos, também foi realizada lavagem da ferida, porém o animal não apresentou melhora significativa.

Ao exame físico do paciente foi constatada a presença de ferida perfurante contaminada de 1,0 $\mathrm{cm}$ de diâmetro localizada na região ventral do ramo horizontal da mandíbula esquerda com secreção de conteúdo serosanguinolento. Durante a inspeção detalhada da ferida foi possível introduzir aproximadamente $4,0 \mathrm{~cm}$ de sonda uretral $\mathrm{n}^{\circ} 06$ sendo este achado compatível com presença de fístula no local. Realizou-se sedação com detomidina (Detomidin ${ }^{\circledR}$, Syntec) $0,02 \mathrm{mg} / \mathrm{Kg}$, IV e com auxílio de abridor de boca foi feita a inspeção da cavidade oral, que associada à avaliação radiográfica possibilitou o diagnóstico de fratura no ramo horizontal da mandíbula do lado esquerdo com presença de fístula na região ventral do dente 307 (Sistema Triadan Modificado). Apesar da presença de secreção serosanguinolenta do trajeto fistuloso, a imagem radiográfica não revelou comprometimento sugestivo de infecção da raiz dentária. Após minucioso exame físico do animal, foram realizados hemograma e cultura com antibiograma do material coletado por swab da fístula.

O hemograma revelou leucocitose com desvio à esquerda, e Proteus sp. foi isolada na cultura. $\mathrm{O}$ teste de sensibilidade in vitro realizado com discos padronizados pelo Clinical Laboratory Standards Institute-CLSI (Markey et al., 2013), mostrou sensibilidade a cefalexina, norfloxacina, sulfonamidas, amoxacilina, enrofloxacina, ceftriaxona e resistência à tetraciclina. 
Como protocolo de tratamento optou-se pela osteossíntese da fratura mandibular utilizando placa bloqueada. O procedimento cirúrgico ocorreu após sedação com xilazina $10 \%$ (Equisedan ${ }^{\circledR}$, J.A. Saúde Animal) 0,7 mg/Kg, IV, seguida de quetamina $10 \%$ (Cetamin $^{\circledR}$, Syntec) $2 \mathrm{mg} / \mathrm{Kg}$, IV associado ao diazepan $\left(\mathrm{Compaz}^{\circledR}\right.$, Cristália) 0,1 $\mathrm{mg} / \mathrm{Kg}$, IV e anestesia inalatória com isoflurano (Vetflurano $^{\circledR}$, Virbac) em oxigênio a $100 \%$. O paciente foi mantido durante todo o procedimento cirúrgico em decúbito lateral direito, foi realizada a antissepsia da ferida utilizando água, solução degermante de iodo polivinilpirrolidona, e álcool $70 \%$ e bloqueio do nervo alveolar mandibular com aplicação de $10 \mathrm{ml}$ de lidocaína $2 \%$ sem vasoconstritor (Xylestesin ${ }^{\circledR}$, Cristália) ao nível do forame mentual.

Foi realizada incisão da pele na porção ventrolateral da mandíbula no ramo horizontal esquerdo, seguido do desbridamento cirúrgico e lavagem com solução fisiológica do trajeto fistuloso assim como do foco de fratura. A osteossíntese foi realizada com uso de duas placas bloqueadas de $3,5 \mathrm{~mm}$ (Cãomédica ${ }^{\circledR}$ ), uma posicionada na região ventral e outra na face lateral da mandíbula (Figura 1). Seguiu-se a implantação local de cimento ósseo acrílico (Ósteo-Class, Baumer $\left.^{\circledR}\right)$ impregnado com gentamicina (Gentatec ${ }^{\circledR}$, Chemitec), $100 \mathrm{mg}$ de gentamicina/2 g do cimento ósseo, e de 4 esponjas de colágeno (Hemospon ${ }^{\circledR}$, Maquira) impregnada com gentamicina.

Foi realizada sutura do tecido subcutâneo e da pele e o paciente foi medicado com penicilina procaína $\left(\right.$ Penfort $^{\circledR}$, Ourofino Saúde Animal) $22.000 \mathrm{UI} / \mathrm{Kg}$, IM a cada 24 horas, durante sete dias, gentamicina $\left(\right.$ Gentatec $^{\circledR}$, Chemitec) 6,6 $\mathrm{mg} / \mathrm{Kg}$, IV a cada 24 horas durante 21 dias. Fenilbutazona (Equipalazone Injetável ${ }^{\circledR}$, Marcolab) 2,2 mg/Kg, IV a cada 24 horas durante cinco dias, e omeprazol (Gastrozol Pasta ${ }^{\circledR}$, Marcolab) dose $1,5 \mathrm{mg} / \mathrm{Kg}$, via oral a cada 24 horas durante sete dias. Foi realizado curativo com solução aquosa de clorexidina $0,12 \%$, duas vezes ao dia. O paciente recebeu alimentação pastosa (ração comercial e feno umedecido em água) durante quatro semanas após a cirurgia, tendo acesso gradativo à alimentação sólida.

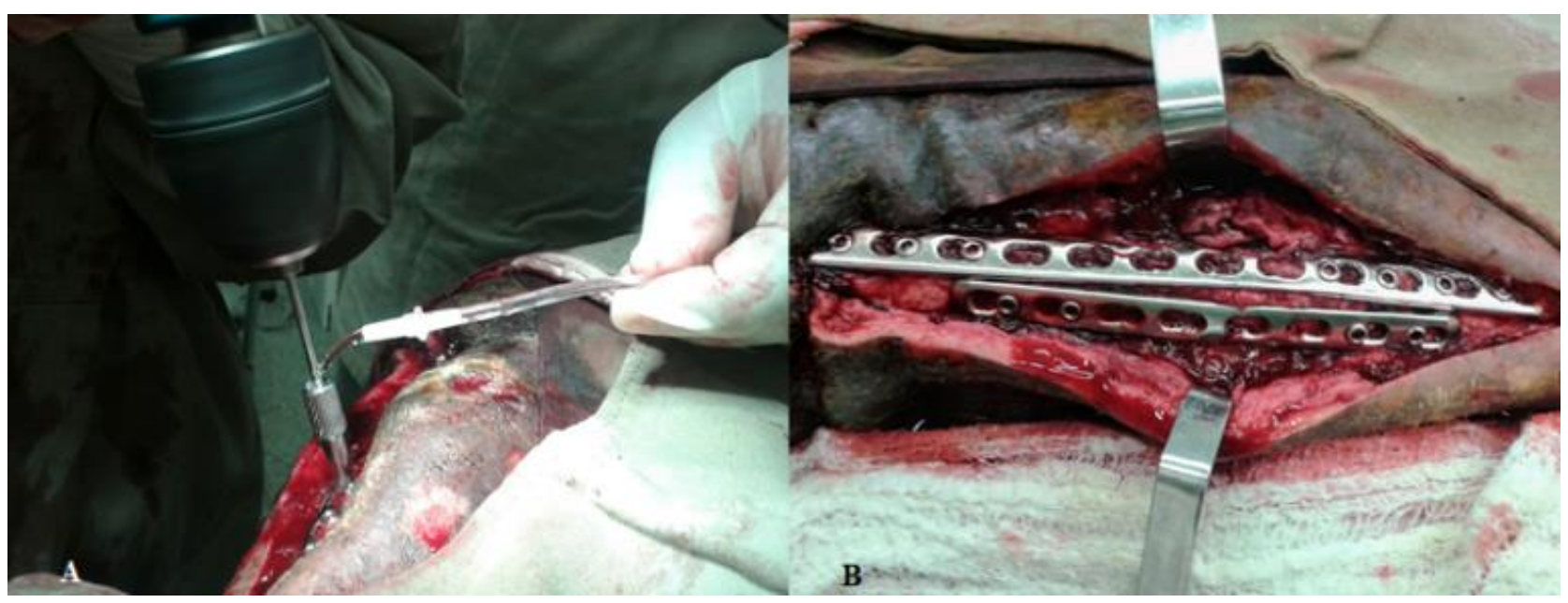

Figura 1. Ilustração da osteossíntese realizada no ramo horizontal da mandíbula esquerda em equino. A) Uso de solução fisiológica para evitar o aquecimento durante a perfuração necessária para fixação da placa bloqueada com parafuso. B) Imagem imediata após o implante de duas placas bloqueadas na face lateral e ventral da mandíbula.

Após sete dias do procedimento cirúrgico notou-se presença de secreção purulenta na ferida, assim, optou-se por substituir o antimicrobiano penicilina procaína por ceftiofur $\left(\right.$ Topcef $^{\circledR}$, Pearson Saúde Animal) 4,4 mg/Kg, IM a cada 24 horas durante 14 dias. Com a nova associação antimicrobiana houve controle do processo infeccioso local e após o término das medicações, depois de 28 dias de internação, o paciente recebeu alta médica, voltando ao HV após quatro meses do procedimento cirúrgico para a remoção dos implantes.

Ao retorno, foi realizado exame radiográfico, que evidenciou consolidação do foco de fratura e controle do processo infeccioso local. $\mathrm{O}$ paciente foi conduzido à cirurgia para remoção das duas placas bloqueadas e do cimento ósseo, instituiu-se um novo protocolo de tratamento à base de ceftiofur (Topcef ${ }^{\circledR}$, Pearson Saúde Animal) $4,4 \mathrm{mg} / \mathrm{Kg}$, IM a cada 24 horas durante 7 dias, 
fenilbutazona (Equipalazone Injetável ${ }^{\circledR}$, Marcolab) $2,2 \mathrm{mg} / \mathrm{Kg}$, IV a cada 24 horas durante três dias, e omeprazol (Gastrozol Pasta ${ }^{\circledR}$, Marcolab) 1,5 $\mathrm{mg} / \mathrm{Kg}$, via oral a cada 24 horas durante sete dias. Assim como curativo com solução aquosa de clorexidina $0,12 \%$, duas vezes ao dia até a remoção da sutura após 10 dias da segunda intervenção cirúrgica. Nova radiografia da região foi realizada após dois meses da retirada dos implantes evidenciando completa cicatrização do foco de fratura.

\section{Discussão}

O trauma com fratura na região da face descrito no presente relato de caso é compatível com outros estudos envolvendo fratura da mandíbula em equinos (Valadão et al., 1994; Alves et al., 2008; Auer, 2012; Nóbrega et al., 2013).

O exame radiográfico realizado no caso relatado, associado ao adequado planejamento cirúrgico prévio possibilitou o sucesso do implante das placas sem evidência do comprometimento da raiz dentária ou qualquer outro tipo de complicação. É recomendada a utilização de exames complementares adicionais como a tomografia computadorizada para o diagnóstico e planejamento da cirurgia, além do desenvolvimento da osteossíntese guiada por fluoroscopia para evitar possível dano da raiz dentária causada pelos parafusos durante $\mathrm{o}$ implante das placas bloqueadas (Kuemmerle et al., 2009), estes exames não foram realizados no caso relatado por ainda não estarem disponíveis no HV desta instituição.

A opção pelo uso da placa bloqueada ao invés da cerclagem para a osteossíntese do caso relatado mostrou-se adequada. Ainda que a cerclagem tenha custo relativo mais baixo, associado à versatilidade de sua aplicação em casos de fraturas rostrais da mandíbula (Nóbrega et al., 2013), a utilização da placa promove melhor estabilidade do foco de fratura no bloqueio da força de flexão da mandíbula, sendo indicada em casos de fraturas instáveis localizadas no diastema, localizadas no ramo horizontal caudal ou ramo vertical da mandíbula (Kuemmerle et al., 2009). Há relato do uso de cerclagem associado à placa bloqueada para osteossíntese da fratura de mandíbula (Kuemmerle et al., 2009), esta associação é indicada em casos do implante da placa na superfície ventral da mandíbula para a melhor estabilidade do foco de fratura (Auer, 2012).
O uso da placa bloqueada no caso de fratura da mandíbula aqui relatado, mesmo que seja mais dispendioso, é justificado pelos princípios biológicos da osteossíntese através da aplicação extra-periosteal sem compressão entre osso e placa, evitando comprometimento adicional da vascularização de fragmentos ósseos, consequentemente diminuindo o risco do sequestro ósseo e aumentando a chance de consolidação (Kuemmerle et al., 2009). Embora as vantagens das placas para osteossíntese de fraturas da mandíbula em equinos sejam evidentes, ainda não é comum o seu uso, havendo apenas um estudo relatando o sucesso da utilização da placa de compressão dinâmica no Brasil (Nóbrega et al., 2013).

O aumento da secreção purulenta advinda da ferida após sete dias da intervenção cirúrgica evidenciou clinicamente a não eficácia da ação antimicrobiana da associação da penicilina com a gentamicina. Mesmo sem o resultado do antibiograma neste momento, optou-se pela imediata substituição do antimicrobiano penicilina pelo ceftiofur e em poucos dias após a alteração esta mostrou ser uma decisão correta baseado na significativa diminuição da secreção purulenta da ferida. Estes dados vão de acordo com o relatado por Hayes et al. (2013), que o tempo necessário para a obtenção dos resultados do antibiograma muitas vezes dificulta o estabelecimento de um plano terapêutico preciso e adequado.

A administração de gentamicina local através do uso de esponja de colágeno e cimento ósseo associada à administração sistêmica do fármaco possibilitou considerável aumento da concentração no local, contribuindo com o sucesso da resolução do quadro infeccioso inicialmente instalado. Estes dados estão de acordo com o descrito por Hayes et al. (2013), que afirmam a necessidade de alta concentração do fármaco no local para possibilitar sua penetração no tecido necrosado e no biofilme formado sobre o implante, ampliando a eficácia terapêutica do processo infeccioso.

Apesar de não ser necessária a retirada das placas implantadas em casos de fraturas em equinos adultos (Auer, 2012), as placas bloqueadas assim como o cimento ósseo implantados no caso relatado foram retiradas após quatro meses do procedimento cirúrgico, quando foi possível observar a adequada consolidação da fratura óssea. A opção pela retirada das placas está de acordo com o descrito por Kuemmerle et al. (2009) que removeram as placas de compressão de todos 
equinos que apresentaram infecção associada ao implante, com tempo de retirada variando entre dois a quatro meses após a osteossíntese.

Informações referentes à utilização de placas para osteossíntese de fraturas de mandíbula em equinos são escassas. Do mesmo modo que não é comum a descrição da utilização de implante local de antimicrobianos para a profilaxia ou terapia de processos infecciosos associadas ao foco de fratura na espécie. Ainda que o tratamento relatado tenha maior custo e demanda maior conhecimento técnico e experiência do cirurgião para a sua aplicação, o seu uso é justificado e encorajado frente ao desafio da terapia de casos de fratura exposta de mandíbula ou casos com processo infeccioso ativo no momento do diagnóstico.

As vantagens da associação da placa bloqueada ao uso de antimicrobiano local e sistêmico em casos de foco de fratura da mandíbula expostos são a adequada estabilização do foco de fratura que é necessária para a consolidação óssea, o aumento da concentração do aminoglicosídeo no local, reduzindo a possibilidade da formação de biofilme sobre o implante, favorecendo assim o controle do processo infeccioso. Provavelmente a evolução da consolidação do foco de fratura tivesse sido diferente, caso não tivesse sido utilizada esta técnica no animal atendido. Este relato consta como o primeiro da utilização de placa bloqueada associada ao implante local de antimicrobianos em caso clínico de fratura de mandíbula em equino descrito no Brasil.

\section{Conflito de interesse}

Os autores declaram não existir conflito de interesse.

\section{Referências}

Alves, G.E.S.; Pagliosa, G.M.; Oliveira, H.P.; Gheller, V.A.; Faleiros, R.R. Fraturas odontomaxilares e mandibulares em equídeos tratados por diferentes técnicas de osteossíntese. Arquivo Brasileiro de Medicina Veterinária e Zootecnia, 60(6): 1382-1387, 2008.
Auer, J.A. Mandible, maxilla and skull. In: Fackelman, G.E.; Auer, J.A.; Nunamaker, D.M. (Eds). AO principles of equine osteosynthesis, New York: Thieme, 1999. p.35-56.

Auer, J.A. Craniomaxillofacial disorders. In: Auer, J.A.; Stick, J.A. Equine Surgery, New York: Saunders, 2012. p.1456-1482.

Freitas, F.C.; Agostino, J.M.A.; Moraes, A.B.T.; Brasil, F.B.J. Osteossíntese associada à homeopatia na consolidação óssea de fratura mandibular em equino. Nucleus Animalium, 2(2): 117-122, 2010.

Grassi, L.; Maisetta, G.; Esin, S.; Batoni, G. Combination Strategies to Enhance the Efficacy of Antimicrobial Peptides against Bacterial Biofilms. Frontiers in Microbiology, 8(2409): 1-8, 2017.

Hayes, G.; Moens, N.; Gibson, T. A review of antibiotic implants and applications to veterinary orthopaedic surgery. Veterinary and Comparative Orthopaedics and Traumatology, 26(4): 251-259, 2013.

Kuemmerle, J.M.; Kummer, M.; Auer, J.A.; Nitzl, D.; Fürst, A. Locking compression plate osteosynthesis of complicated mandibular fractures in six horses. Veterinary and Comparative Orthopaedics and Traumatology, 22(1): 54-58, 2009.

Markey, B.; Leonard, F.; Archmbault, M.; Cullinane, A.; Maguire, D. Clinical Veterinary Microbiology. $2^{\text {nd }}$ ed. St. Louis, USA: Mosby Elsevier, 2013. p. 920.

Nóbrega, F.S.; Ferreira, M.P.; Alievi, M.M.; Beck, C.A.C.; Gonzalez, P.C.; Dal-bói, I.S.; Stédile, R. Osteossíntese de mandíbula e maxila em equinos adultos: relato de quatro casos. Arquivo Brasileiro de Medicina Veterinária e Zootecnia, 65(1): 1706-1712, 2013.

Valadão, C.A.A; Marques, J.A.; Padilha Filho, J.G.; Rodrigues, C.A.; Ferreira, H.I. Uso da cerclagem e resina acrílica em fraturas mandibulares dos equídeos. Ciência Rural, 24(2): 323-327, 1994. 